\title{
Marriage Vows and Racial Choices
}

\author{
by Jessica Vasquez-Tokos \\ New York: Russell Sage Foundation, 2017 \\ ISBN 978-0087154-868-9 \\ Softcover, $\$ 35,388$ pp.
}

Reviewed by Gillian Stevens

University of Alberta

People's choices of marriage partners sometimes seem inexplicable to their friends and families, and often seem over-determined by demographic or social constraints to sociologists. In Marriage Vows and Racial Choices, Jessica Vasquez-Tokos delves into why Latino respondents marry either within or outside of their racial/ethnic group, and the ramifications of their marital choices for their cultural practices and racial consciousness. Her analyses are based on semi-structured interviews with 109 respondents from 49 families in California and Kansas. In these interviews, she inquired about the respondents' racial backgrounds, identity claims, natal and marital families, child-rearing strategies, and cultural practices.

The respondents' narratives vividly show that marital choices are influenced by a complex array of individual, family, and contextual factors. Some of Vasquez-Tokos' respondents implicitly (and sometimes explicitly) referred to out-marriage to a white partner as a means of increasing their own class-race status. Other respondents preferred non-white partners who shared the experience of being members of marginalized racial groups. Still others actively sought partners outside of their own ethnic racial group in an effort to avoid oppressive gender roles. In a particularly compelling outcome, some of the author's Latina respondents with domineering fathers veered away from choosing Latino husbands in an effort to avoid reproducing their natal family dynamics.

Unlike most other studies of racial in-marriage and out-marriage, Vasquez-Tokos pays attention to important issues and perspectives that are often ignored. For example, she considers the modification or maintenance of cultural practices and racial identities from the vantage point of both partners in the marriage rather than just one. The inclusion of adult children among her respondents also means that she is able to show disparities in how children of interracial marriages construct their own racial identities. Finally, the study pays attention to how the demographic context influences people's tolerance, and expectations, of interracial marriage.

Overall, scholars interested in intermarriage or racial identities will find this book well worth reading. Vasquez-Tokos' research is well designed, she uses a strong theoretical stance, and her observations and conclusions are insightful and compelling. 